\title{
Awareness among Patients with T2DM regarding the Disease at a Tertiary Care Referral Center
}

\author{
${ }^{1}$ Sukhpal Kaur, ${ }^{2}$ Lata Mandal, ${ }^{3}$ Priya Nair, ${ }^{4}$ Narinder Kaur, ${ }^{5}$ Pragya Pathak, ${ }^{6}$ Anil Bhansali
}

\begin{abstract}
Objective: To assess the knowledge of patients with T2DM regarding their disease at a tertiary care referral centre.

Patients and methods: Using purposive sampling technique, a total of 200 patients of diabetes were enrolled. The pretested questionnaire consisting of 40 items with maximum score of 40 was administered to the participants after appropriate validation. Information was obtained regarding the demographic variables, presenting symptoms of diabetes, and awareness of the subjects regarding their disease. The data was analyzed by using SPSS version 16.
\end{abstract}

Results and conclusion: Mean age of the subjects was $54.2 \pm 1.2$ years with the range of 16 to 80 years. More than half $(52.5 \%)$ were women and $54.5 \%$ were in the age group of 41 to 60 years, and $50.5 \%$ belonged to urban locality. Majority were married $(96.5 \%)$. Polyuria was the presenting symptoms in $43.5 \%$ of patients. The mean knowledge score was $26.0 \pm$ 8.9 out of 40 (maximum attainable score) with the range of 3 to 39 . More than half $(63 \%)$ of the patients achieved good $(>60 \%)$ and above category of knowledge score. The patients with higher education status, male, and with positive family history of diabetes had significantly more knowledge score $(r=0.3$, $-0.2,-0.2, p<0.01$ for all).

Conclusion: In the present study, almost two third of the patients with T2DM had good knowledge about the disease; however, more efforts are required to further improve the knowledge among them.

Keywords: Awareness, Knowledge, Diabetes education, Diabetes mellitus.

How to cite this article: Kaur S, Mandal L, Nair P, Kaur N, Pathak P, Bhansali A. Awareness among Patients with T2DM

\footnotetext{
${ }^{1,5}$ Lecturer, ${ }^{2}$ Lieutenant Colonel, ${ }^{3}$ Major, ${ }^{4}$ Principal

${ }^{6}$ Professor and Head

${ }^{1}$ Department of National Institute of Nursing Education Postgraduate Institute of Medical Education and Research Chandigarh, India

${ }^{2}$ Department of Nursing, Armed Forces Medical College, Pune Maharashtra, India

${ }^{3}$ Department of Nursing, Command Hospital, Eastern Command Kolkata, West Bengal, India

${ }^{4}$ Department of Nursing, Saraswati College of Nursing, Mohali Punjab, India

${ }^{5}$ College of Nursing, All India Institute of Medical Sciences New Delhi, India

${ }^{6}$ Department of Endocrinology, Postgraduate Institute of Medical Education and Research, Chandigarh, India
}

Corresponding Author: Sukhpal Kaur, Lecturer, Department of National Institute of Nursing Education, Postgraduate Institute of Medical Education and Research, Chandigarh, India, Phone: 09888536964, e-mail: sukhpal.trehan@yahoo.in regarding the Disease at a Tertiary Care Referral Center. J Postgrad Med Edu Res 2014;48(3):117-122.

Source of support: Nil

Conflict of interest: None

\section{INTRODUCTION}

Diabetes is a worldwide epidemic. Because of urbanization and change in life style, its incidence is increasing. It is estimated that more than 180 million people worldwide have diabetes. This number is likely to be more than double by 2030 . In developing countries, the number of people with diabetes will increase by $150 \%$ in the next 25 years. At present, India is considered as the diabetes capital of the world. There are approximately 3.5 crores diabetic people in India, and this figure is expected to increase approximately upto 8 crores by $2030 .{ }^{1-3}$ However, recent data from China scores over India with estimated population of subjects with diabetes around 92.4 million. ${ }^{4}$ The prevalence of diabetes mellitus is progressively rising possibly because of increasing trend for sedentary and stressful lifestyle, and redefinition of diagnostic criteria of diabetes. ${ }^{5}$

Diabetes, being a chronic and costly disease, is an important public health problem. It is associated with high morbidity and mortality rate. The metabolic dysregulation due to diabetes mellitus consequently results in micro- and macrovascular complications that impose a tremendous burden on the individual with diabetes and on the health care system as well. ${ }^{6}$ Although long-term complications of diabetes develop gradually, they can eventually be disabling and even life-threatening. People with diabetes are 20 times more prone to retinopathy, have six times higher risk for stroke, have two times the risk of coronary events, are five times more prone to renal diseases and are 20 times more prone to lower limb amputations. ${ }^{7}$

Proper management requires patients to be aware of the nature of the disease, its risk factors, its treatment and complications. Patient education is a key component to diabetes management. It is regarded as an essential part in diabetes care as it enables people with diabetes for selfcare. ${ }^{8,9}$ The American Association of Diabetes Educators have outlined seven self care behaviors as the diabetes self-management core outcomes measurements which include being active, eating, medication taking, monitoring blood glucose, problem solving especially for low blood 
glucose levels, and sick days, reducing risks of diabetes complications, and living with diabetes. ${ }^{10}$

The current study attempts to assess the awareness of various aspects regarding diabetes in patients attending endocrinology OPD of a tertiary care hospital.

\section{PATIENTS AND METHODS}

The study was conducted in the diabetes clinic of Post Graduate Institute of Medical Education and Research, Chandigarh. Using purposive sampling technique, a total of 200 diagnosed T2DM patients were included in the study. After obtaining informed consent, the pretested questionnaire consisting of 40 items was administered to the participants. Each item was scored for correct response. Score 1 was given to the correct response and 0 to incorrect and do not know response. Information was obtained regarding the demographic variables, presenting symptoms of diabetes, and awareness of the subjects regarding the disease. The knowledge score was categorized as poor, average, good, very good, and excellent as per the scores obtained by the subjects in various parameters of the disease under study, i.e. $<50 \%, 51$ to $60 \%, 61$ to $75 \%, 76$ to $90 \%$, and $>90 \%$, respectively. Content validity of the questionnaire was established by circulating the tool among the experts in the field of endocrinology. Pearson's correlation was applied to examine the association among the demographic variables and the knowledge score of the subjects.

\section{CALCULATION OF SAMPLE SIZE}

Sample size was calculated by assuming the prevalence of diabetes as $15 \%$, and considering the relative precision of $0.05 \%$. It was calculated as $\mathrm{N}=4 \mathrm{pq} / \mathrm{d}^{2}=(4 \times 0.15 \times$ $0.85) / 0.05 \times 0.05=204$, where $p$ is the proportion of the estimated population and $q=(1-p), d$ representing the relative precision. The sample size calculated was 204 and a round of figure of 200 was taken up for the study.

\section{RESULTS}

\section{Demographic Characteristics of the Subjects}

Mean age of the subjects was $54.2 \pm 1.2$ years with the range of 16 to 80 years. More than half $(52.5 \%)$ were women, $54.5 \%$ were in the age group of 41 to 60 years, and $50.5 \%$ belonged to urban locality. By religion, $70 \%$ were Hindu. Majority were married (96.5\%) (Table 1).

\section{Symptoms at Onset of Diabetes}

Mean age of the subjects at the onset of diabetes was 45.1 \pm 11.8 years with the range of 12 to 77 years. Polyuria was the presenting symptom in $43.5 \%$ of diabetes. It was followed by tiredness and excessive thirst by 39 and $37 \%$ of the respondents, respectively. Around one-fourth (27\%) were asymptomatic at the time of diagnosis. Delayed wound healing and pruritis vulvi were reported by 12 and $6.5 \%$ patients, respectively. Around half (45.5\%) had family history of diabetes (Table 2).

\section{Mean Knowledge Score}

The maximum attainable score was 40 . The mean knowledge score of the subjects was $26.0 \pm 8.9$ with the range of 3 to 39 . More than half of the subjects had score in the category of good and very good. Excellent knowledge score, i.e. more than $90 \%$ was attained by only $10 \%$ of the subjects (Table 3 ).

\section{Knowledge Score regarding Diabetes as per the Demographic Variables}

Table 4 depicts the knowledge score as per the demographic variables of the subjects. There was a significant correlation of knowledge score with gender, education, and family history of diabetes $(\mathrm{r}=-0.2,0.3$, and $-0.2, \mathrm{p}<0.05$ for all $)$.

\section{Knowledge of the Subjects regarding Risk Factors and Etiology of Diabetes}

More than half of the subjects were aware that an individual is prone to develop diabetes if there is a family history of diabetes $(56.5 \%)$ and if the person is overweight (58.5\%). Around $60 \%$ responded that diabetes develops because of either deficiency of insulin in the body (59\%) or more consumption of sweets (61\%) (Table 5).

\section{Knowledge of the Subjects regarding Signs and Symptoms and Investigation of Diabetes}

Majority were aware of the signs and symptoms of diabetes. Frequent urination was correctly answered by $86.5 \%$ subjects.

Table 1: Demographic profile of the subjects $(N=200)$

Demographic data

Age (yrs) n(\%)

- Mean \pm SD: $54.2 \pm 1.2$

- Range: 16-80

Gender

- Male

$95(47.5)$

- Female

$105(52.5)$

Habitat

- Rural

$47(23.5)$

- Town

$52(26)$

- Urban

$101(50.5)$

Religion

- Christian $3(1.5)$

- Muslim

$6(3)$

- Sikh

$51(25.5)$

- Hindu $140(70)$

Marital status

- Divorced/separated $1(0.5)$

- Unmarried 6 (3)

- Married

$193(96.5)$ 
Table 2: Presenting symptoms of diabetes in study subjects $(\mathrm{N}=200)$

\begin{tabular}{ll}
\hline & $n(\%)$ \\
\hline Age at onset of diabetes (yrs) & \\
- Mean \pm SD: $45.1 \pm 11.8$ & \\
- Range: $12-77$ & \\
Symptoms at onset* & \\
- Polyuria & $87(43.5)$ \\
Tiredness & $78(39)$ \\
- Excessive thirst & $74(37)$ \\
- Asymptomatic & $54(27)$ \\
- Weight loss & $47(23.5)$ \\
- Delayed wound healing & $24(12)$ \\
- Pruritis vulvi & $13(6.5)$ \\
Family history of diabetes & \\
- Yes & $91(45.5)$ \\
- No & $109(54.5)$ \\
\hline
\end{tabular}

*More than one symptom were reported by the subjects

Table 3: Mean knowledge score of the subjects

\begin{tabular}{ll}
\hline Maximum score: $40, N=200$ & $n(\%)$ \\
\hline Mean knowledge score & \\
- Mean \pm SD: $26.04 \pm 8.9$ & \\
- Range: $3-39$ & \\
Knowledge score & \\
- Poor: $<50 \%$ & $52(26)$ \\
- Average: $51-60 \%$ & $23(11.5)$ \\
- Good: $61-75 \%$ & $48(24)$ \\
- Very good: $76-90 \%$ & $56(28)$ \\
- Excellent: $>91 \%$ & $21(10.5)$ \\
\hline
\end{tabular}

It was followed by tiredness $(82.5 \%)$ and excessive thirst $(81 \%)$. The range for fasting blood glucose levels in healthy subjects was known to $60 \%$ subjects; however, $43 \%$ rightly responded regarding the postprandial blood glucose levels. Majority was aware regarding the routine investigations like checking the blood pressure (89.9\%), eye check up (89.9\%), urine testing (84\%), and blood cholesterol level (82.5\%) which should be regularly done by a diabetes patient (Table 5).

\section{Awareness of the Subjects regarding Insulin Use}

Half of the subjects responded that insulin injection should be taken half an hour before meal and only $29 \%$ were aware that site of insulin injection should be rotated for better effect of the drug. A total of $63 \%$ answered that insulin should be stored in fridge and only $37 \%$ were of the opinion that insulin vial should be brought to the room temperature before administration (Table 5).

\section{Awareness regarding Signs and Symptoms and Management of Hypoglycemia}

Regarding signs and symptoms of hypoglycemia, 64\% answered as dizziness, however, loss of consciousness and slurred speech were reported by 58.5 and $47.5 \%$, respectively. About the management of hypoglycemia, $71.5 \%$ subjects were of the opinion that one should take glucose or juice; however, $60 \%$ reported that one should eat chocolate or biscuits.

Table 4: Knowledge score regarding diabetes as per the demographic variables $(N=200)$

\begin{tabular}{|c|c|c|c|c|}
\hline Variables & $N$ & Mean $\pm S D$ & $r$-value & $p$-value \\
\hline \multicolumn{5}{|l|}{ Age } \\
\hline$-<20$ & 11 & $29.9 \pm 3.7$ & -0.05 & NS \\
\hline$-21-40$ & 32 & $25.6 \pm 8.4$ & & \\
\hline$-41-60$ & 90 & $25.4 \pm 9.5$ & & \\
\hline$-61-80$ & 67 & $26.6 \pm 8.7$ & & \\
\hline \multicolumn{5}{|l|}{ Sex } \\
\hline - Male & 95 & $27.8 \pm 8.4$ & -0.2 & $<0.05$ \\
\hline - Female & 105 & $24.5 \pm 9.0$ & & \\
\hline \multicolumn{5}{|l|}{ Type of family } \\
\hline - Joint & 95 & $25.5 \pm 9.0$ & 0.04 & NS \\
\hline - Nuclear & 105 & $26.7 \pm 8.7$ & & \\
\hline \multicolumn{5}{|l|}{ Habitat } \\
\hline - Rural & 47 & $24.5 \pm 9.8$ & 0.06 & NS \\
\hline - Urban & 101 & $26.8 \pm 8.5$ & & \\
\hline - Town & 52 & $26.0 \pm 8.8$ & & \\
\hline \multicolumn{5}{|l|}{ Education } \\
\hline - Under matric & 86 & $23.5 \pm 9.6$ & 0.3 & 0 \\
\hline - Undergraduate & 95 & $28.2 \pm 8.3$ & & \\
\hline - Postgraduate & 19 & $29.3 \pm 7.8$ & & \\
\hline \multicolumn{5}{|l|}{ Family h/o diabetes } \\
\hline - Yes & 91 & $28.1 \pm 8.0$ & -0.2 & $<0.05$ \\
\hline - No & 109 & $24.1 \pm 9.2$ & & \\
\hline
\end{tabular}


Table 5: Awareness of the subjects regarding various aspects of diabetes

\begin{tabular}{|c|c|}
\hline Items & $\begin{array}{l}\text { Correct } \\
\text { response } n(\%)\end{array}$ \\
\hline \multicolumn{2}{|l|}{ Diabetes is likely to develop if there is: } \\
\hline - Stress & $155(77.5)$ \\
\hline - Overweight & $117(58.5)$ \\
\hline - Family history of diabetes & $113(56.5)$ \\
\hline \multicolumn{2}{|l|}{ Diabetes develops because of: } \\
\hline - More consumption of sweets & $122(61)$ \\
\hline - Deficiency of insulin in the body & $118(59)$ \\
\hline \multicolumn{2}{|l|}{ Sign and symptoms of diabetes are: } \\
\hline - Frequent urination & $173(86.5)$ \\
\hline - Tiredness & $165(82.5)$ \\
\hline - Excessive thirst & $162(81)$ \\
\hline - Excessive hunger & $152(76)$ \\
\hline - Delayed wound healing & $150(75)$ \\
\hline \multicolumn{2}{|l|}{$\begin{array}{l}\text { Fasting blood glucose levels in a normal } \\
\text { person is: }\end{array}$} \\
\hline$-70-100 \mathrm{mg} / \mathrm{dl}$ & $120(60)$ \\
\hline \multicolumn{2}{|l|}{$\begin{array}{l}\text { Blood glucose levels two hours after } \\
\text { meal are: }\end{array}$} \\
\hline$-110-140 \mathrm{mg} / \mathrm{dl}$ & $86(43)$ \\
\hline \multicolumn{2}{|l|}{ Regarding investigations: } \\
\hline - Blood pressure & $179(89.5)$ \\
\hline - Eye check up & $179(89.5)$ \\
\hline - Urine test & $168(84)$ \\
\hline - Blood cholesterol level & $165(82.5)$ \\
\hline - Foot check up & $146(73)$ \\
\hline \multicolumn{2}{|l|}{ Insulin injection should be taken: } \\
\hline - Half an hour before meal & $101(50.5)$ \\
\hline \multicolumn{2}{|l|}{$\begin{array}{l}\text { Site of insulin injection should be rotated } \\
\text { in order: }\end{array}$} \\
\hline - To avoid infection & $82(41)$ \\
\hline - To prevent the wound formation & $72(36)$ \\
\hline \multicolumn{2}{|l|}{$\begin{array}{l}\text { Important things to be kept in mind before } \\
\text { taking insulin injection: }\end{array}$} \\
\hline $\begin{array}{l}\text { - Type of insulin as per the prescription of } \\
\text { doctor }\end{array}$ & $93(46.5)$ \\
\hline - Dose of insulin & $86(43)$ \\
\hline - Temperature of insulin & $74(37)$ \\
\hline - Insulin should be kept in fridge & $126(63)$ \\
\hline \multicolumn{2}{|l|}{$\begin{array}{l}\text { Signs and symptoms of decreased blood } \\
\text { glucose level are }\end{array}$} \\
\hline - Dizziness & $128(64)$ \\
\hline - Increased perspiration & $117(58.5)$ \\
\hline - Loss of consciousness & $117(58.5)$ \\
\hline - Slurred speech & $95(47.5)$ \\
\hline \multicolumn{2}{|l|}{$\begin{array}{l}\text { What should be done if blood glucose level } \\
\text { is decreased }\end{array}$} \\
\hline - Taking glucose water or juice & $143(71.5)$ \\
\hline $\begin{array}{l}\text { - Eating chocolate or biscuits regarding } \\
\text { food }\end{array}$ & $120(60)$ \\
\hline $\begin{array}{l}\text { Eatables containing starch, e.g. rice, } \\
\text { pasta, bread, potato, etc. affect the blood } \\
\text { glucose levels }\end{array}$ & $162(81)$ \\
\hline $\begin{array}{l}\text { - All eatables containing sugar increase the } \\
\text { blood glucose level }\end{array}$ & $159(79.5)$ \\
\hline
\end{tabular}

Contd...
Contd...

- Fresh fruit juices even without sugar

$69(34.5)$ should be consumed in limited quantity only

Regarding exercises

- Exercises help to decrease the blood $160(80)$ glucose.

Regarding foot care

- One should soak the feet in lukewarm 127 (63.5) water

- Foot ulcers heals slowly

- One should get the foot checked up at $161(80.5)$ regular interval

- Toe nails should be cut straight

- Shoes should be very soft

$161(80.5)$

\section{Awareness of the Subjects regarding Food and Role of Exercise in Diabetes}

More than $80 \%$ were aware that all eatables containing starch, e.g. rice, pasta, bread, potato, etc, and sugar affect the blood glucose level. Only $34.5 \%$ responded that fresh fruit juices even without sugar should be consumed in limited quantity only. A total of $80 \%$ subjects rightly responded that exercise help to reduce the blood glucose level (Table 5).

\section{Awareness of the Subjects regarding Foot Care}

One should get their feet checked up at regular interval and should wear the soft shoes was known to $80.5 \%$. Three fourth $(74.5 \%)$ were aware that toe nails should be cut straight (see Table 5).

\section{DISCUSSION}

This study shows that two third of the patients had good knowledge regarding symptomatology, relevant investigations and foot care at this tertiary care referral center. However, they had poor knowledge about insulin therapy.

Treatment of any disease in today's context needs to start with patient education as well as information of expected outcomes, side effects, and alternatives available. This become more pertinent to chronic treatable diseases like diabetes, hypertension, coronary artery disease, bronchial asthma and rheumatoid arthritis, a few to mention. Patients need to understand the nature of the disease, the treatment modalities being used and the future prospects of the illness.

Diabetes is a chronic and treatable disease and the patients have to live with the disease for the rest of their life. In this situation, they need to have a good knowledge regarding the role of various dietary items, obesity and weight management, and importance of activity and exercise in their life. No one can learn those things by default. Awareness from media and a nice role played by various other organizations regarding information and education of 
common man plays an important role as far as knowledge of people is concerned. In the current study, more than one third of the subjects did not know that obesity is a risk factor for diabetes and the role of consumption of sweets in the control of diabetes. Awareness of these factors can go a long way in the primary prevention of diabetes and other noncommunicable diseases.

Diabetes can be well managed and its complications can be prevented by increasing awareness of the disease among the patients. Patients with diabetes mellitus often lack sufficient knowledge about their disease and thus, frequently have poor self-management skills. In the current study, more than half of the subjects were in the good and very good category of knowledge score. The patients were asked more of the general questions. An attempt was made to assess the knowledge regarding the risk factors, etiological factors, signs and symptoms, the common investigations the diabetes patient should be undergoing, use of insulin, signs and symptoms and management of hypoglycemia, awareness regarding food, the role of exercises in the management of diabetes, and their knowledge regarding foot care. It was observed that for the items like symptomatology of diabetes, the common investigations the patients should be undergoing, the foods affecting the blood glucose level, the role of exercises and the foot care, more than $75 \%$ of the subjects were aware. Though for the other items like risk factors of diabetes, etiology of diabetes, the fasting blood glucose level, the time of taking insulin injection, the storage of insulin, signs and symptoms and management of hypoglycemia, half of the subjects were aware. This could be explained by the fact that in the current study more than half of the subjects were in the age group of 41 to 60 years, belonged to urban locality, were educated and $45.5 \%$ had the family history of diabetes. In a study carried out in Glasgow, it was reported that as the education level rises and as the duration of diabetes prolongs the knowledge of diabetes patients increased. ${ }^{11}$ Similar findings have been reported from India also. ${ }^{12}$ The results are inconsistent with another study where only $14 \%$ of the participants had a good knowledge of diabetes. ${ }^{13}$ Hashmni et al have also reported that the general awareness of the patients regarding diabetes mellitus in their study was poor. ${ }^{14}$ However, another study done in Singapore showed that $60 \%$ of the subjects had correct knowledge about the origin of the disease. ${ }^{15}$

In the current study, the mean age of the subjects was 54.2 \pm 1.2 years and there were more female patients. Arslantas et $\mathrm{al}^{16}$ and Moodley et $\mathrm{al}^{17}$ also had more female patients in their studies.

Hypoglycemia, which may be an important lifethreatening event atleast sometimes in the life of every diabetes patient, is an important part of education. In fact, every patient when initiated on drug treatment needs to be told about symptoms of hypoglycemia and emergency steps to be taken by him or her in the case of eventuality. A study carried out at a tertiary care hospital, it has been reported that $48.5 \%$ did not know about the symptoms of hypoglycemia. Yet, $76.2 \%$ knew that sweets should be consumed if they are hypoglycemic. ${ }^{18}$ In our study, three fourth subjects were of the opinion that one should take glucose or juice at the time of hypoglycemia. Similarly, $40 \%$ of diabetes patients were not aware about the normal fasting glucose levels, whereas $57 \%$ patients did not know about the normal post prandial blood glucose levels. Without knowing these values, what control of glucose these patients will tend to achieve, is anybody's guess? Shah et al had documented in their study that nearly $50 \%$ were aware regarding the complications of diabetes. $^{19}$

Now the question is that how the levels of knowledge of diabetes can be improved in our patients. The shear number of patients and the quantum of rush in the institutes tell us about the challenge facing the authorities. It is humanly not conceivable that any meaningful chore of education can be possible in these OPDs. Constraints of manpower are there. But the loss in the form of morbidity, mortality, and manhours lost if kept under consideration, it may turn out to be finally cost-effective to depute good number of dedicated paramedical staff members well trained in diabetes and patient education. In addition to managing huge number of patients, if some more component of better quality could be added to the patient care, it will go a long way in creating a healthy society for the nation. It will also help to check the monstrous spread of epidemic of diabetes and other related noncommunicable diseases.

The limitation of the study include small sample size, but the strength of the study is that a very elaborative and validated questionnaire covering almost all the aspects of the disease is used to assess the knowledge of the subjects under study.

\section{REFERENCES}

1. Ramachandran A, Snehalatha C, Baskar AD, Mary S, Kumar CK, Selvam S, Catherine S, Vijay V. Temporal changes in prevalence of diabetes and impaired glucose tolerance associated with life style transition occurring in rural population in India. Diabetologia 2004;47(5):860-865.

2. King H, Aubert RE, Herman W. Global burden of diabetes, 1995-2025: prevalence, numerical estimates, and projections. Diabetes Care 1998;21(9):1414-1431.

3. Gupta V, Suri P. Diabetes in elderly patients. JK Practitioner 2002;91:258-259.

4. Yang W, Lu J, Weng J, Jia W, Ji L, Xiao J, Shan Z, Liu J, Tian H, $\mathrm{Ji}$ Q, et al. Prevalence of diabetes among men and women in China. N Engl J Med 2010 25;362(12):1090-1101. 
5. Balkau B, Eschwege E, Tichet J, Marre M. Proposed criteria for the diagnosis of diabetes: evidence from a French epidemiological study. Diabetes Metab 1997;23(5):428-434.

6. Fauci AS, Braunwald E, Kasper DL, Hauser SL, Longo DL, Jameson JL. Harrison's Principles of Internal Medicine, Vol. II, 7th ed: Mc Graw-Hill Companies; 2008.

7. Joshi JK, Srishyla MV. Novo Nordisk Diabetes Update 2004 proceedings. Laxmi Graphics, Bangalore.

8. Fritsche A, Stumvoll M, Goebbel S, Reinauer KM, Schmülling RM, Häring HU. Long term effects of a structured inpatient diabetes teaching and treatment programme in type 2 diabetic patients: influence of mode of follow-up. Diabetes Res Clin Pract 1999;46(2):135-141.

9. Nicolucci A, Ciccarone E, Consoli A, Di Martino G, La Penna G, Latorre A, Pandolfi A, Vitacolonna E, Capani F. Relationship between patient practice-oriented knowledge and metabolic control in intensively treated type 1 diabetic patients: results of the validation of the knowledge and practices diabetes questionnaire. Diabetes Nutr Metab 2000;13(5):276-283.

10. Mulcahy K, Maryniuk M, Peeples M, Peyrot M, Tomky D, Weaver T, Yarborough P. Diabetes self-management education core outcomes measures. Diabetes Edu 2003;29(5):768-803.

11. Baradaran H, Knill-Jones R. Assessing the knowledge, attitudes and understanding of type 2 diabetes amongst ethnic groups in Glasgow, Scotland. Practical Diabetes Int 2004;21(4):143-148.
12. Shobana R, Pramila L, Shyamala P, Mohan V, Ramachandren A, Viswanathan M. Assessment of background knowledge of diabetes mellitus in diabetic patients. J Diab Assoc India 1989; 29:70-74.

13. Rafique G, Shaikh F. Identifying needs and barriers to diabetes education in patients with diabetes. J Pak Med Assoc 2006 Aug;56(8):347-352.

14. Hashmi NR, Manzoor I, Daud S. Diabetes mellitus: awareness among individuals attending out patient department of Ghurki Trust teaching hospital. Professional Med J 2008;15(1):96-100.

15. Wee HL, Ho HK, Li SC. Public awareness of diabetes mellitus in Singapore. Singapore Med J 2002;43(3):128-134.

16. Arslantas D, Unsal A, Metintas S, Koc F. Knowledge of diabetic patients about diabetes at the primary stage in Eskisehir, Turkey. Pak J Med Sci 2008;24(2):263-268.

17. Moodley LM, Rambiritch V. An assessment of the level of knowledge about diabetes mellitus among diabetic patients in a primary healthcare setting. SA Fam Pract 2007;49(10):16a-16d.

18. Gulabani M, John M, Isaac R. Knowledge of diabetes, its treatment and complications amongst diabetic patients in a tertiary care hospital. Indian J Community Med 2008;33(3):204-206.

19. Shah VN, Kamdar PK, Shah N. Assessing the knowledge, attitudes and practice of type 2 diabetes among patients of Saurashtra region, Gujarat. Int J Diabetes Dev Ctries 2009;29(3): 118-122. 